\title{
GAMBARAN KECEMASAN EVALUATIF PADA MAHASISWA PADA UNIVERSITAS $X$
}

\author{
Chaterine Angellim ${ }^{1}$, Monty P. Satiadarma ${ }^{2}$, Untung Subroto ${ }^{3}$ \\ ${ }^{1}$ Program Studi Magister Psikologi Profesi, Universitas Tarumanagara, Jakarta \\ Email: Chaterine.717172008@stu.untar.ac.id \\ ${ }^{2}$ Fakultas Psikologi, Universitas Tarumanagara, Jakarta \\ Email: montys@fpsi.untar.ac.id \\ ${ }^{3}$ Fakultas Psikologi, Universitas Tarumanagara, Jakarta \\ Email: Untungs@fpsi.untar.ac.id
}

Masuk : 17-03-2020, revisi: 28-10-2020, diterima untuk diterbitkan : 29-10-2020

\begin{abstract}
Test anxiety is a set of cognitive, behavioral, and physiological responses which are followed by concerns about the possible negative outcomes of failure on the test or similar evaluative conditions. Excessive degree of test anxiety can result in negative impacts including poor school performance, poor examination performance, mental distress, cognitive impairment, and poor health. This study was aimed to find out test anxiety level experience by college students. This study uses quantitative approach with 207 students from one of private univerity in Jakarta. Data was collected using the Test Anxiety Inventory. The results showed that from 207 participants, there were 119 (57\%) students with low test anxiety levels, 85 (41\%) students with moderate test anxiety levels, 3 (1\%) students with high test anxiety levels.
\end{abstract}

Keywords: test anxiety, college students

\begin{abstract}
ABSTRAK
Test anxiety atau kecemasan evaluatif adalah kumpulan dari respon perilaku, kognitif, dan fisiologis yang disertai dengan kehawatiran akan kemungkinan konsekuensi negatif dari kegagalan pada tes atau situasi evaluatif yang serupa. Kecemasan evaluatif yang tinggi dapat berdampak negatif bagi penyandangnya seperti misalnya prestasi sekolah yang rendah, performa tes yang buruk, gangguan kognitif, kesehatan yang buruk dan tekanan psikologis. Tujuan penelitian ini adalah untuk mengetahui gambaran kecemasan evaluatif pada mahasiswa. Penelitian ini menggunakan pendekatan kuantitatif pada 207 mahasiswa di salah satu universitas swasta di Jakarta. Pengukuran kecemasan evaluatif menggunakan Test Anxiety Inventory. Hasil penelitian menunjukkan bahwa dari 207 partisipan, terdapat $119(57 \%)$ mahasiswa dengan tingkat kecemasan evaluatif rendah, 85 (41\%) mahasiswa dengan tingkat kecemasan evaluatif sedang, 3 (1\%) mahasiswa dengan tingkat kecemasan evaluatif tinggi.
\end{abstract}

Kata Kunci: test anxiety, kecemasan evaluatif, mahasiswa

\section{PENDAHULUAN \\ Latar Belakang}

Kecemasan adalah hal yang normal sering ditemui dalam kehidupan sehari-hari (Helsley \& Vanin, 2008). Hampir semua orang pernah mengalami rasa cemas pada waktu tertentu yang dapat memengaruhi performa dan efektivitas individu pada situasi tersebut (Javanbakht \& Hadian, 2014). Tingkat kecemasan yang wajar dapat bersifat adaptif dan dapat membantu individu untuk mempersiapkan respon perilaku tertentu seperti mempersiapkan respon akan kemungkinan ancaman yang akan datang (Helsley \& Vanin, 2008; Grupe \& Nitschke, 2013). Akan tetapi, pada sisi lain kecemasan juga menghambat sebagian orang untuk berkinerja dengan baik. Sehingga hal ini dapat mengganggu dan melumpuhkan aktivitas individu (Helsley \& Vanin, 2008).

Secara umum gangguan kecemasan memiliki prevalensi tertinggi dibandingkan dengan gangguan kesehatan mental lainnya di dunia (Ritchie \& Roser, 2018). Berdasarkan data tahun 2016, sekitar $4 \%$ atau setara 275 juta jiwa dari populasi dunia mengalami gangguan kecemasan. 
Di Indonesia sendiri berdasarkan data tahun 2018, prevalensi individu yang mengalami gangguan kesehatan emosional -yang ditunjukkan dalam gejala depresi dan kecemasan; mencapai sekitar 26,5 juta jiwa (Kemenkes, 2018). Jumlah ini meningkat 4\% sejak lima tahun terakhir dari sekitar 14 juta jiwa (Kemenkes, 2016; Kemenkes 2018).

Secara umum, gangguan kecemasan rata-rata muncul di usia 21.1 - 34.9 tahun (de Lijster et al., 2017). Menurut Pedrelli et al. (2015) sebagian besar masalah gangguan kesehatan mental memiliki titik puncak untuk muncul saat masa dewasa awal. Hal ini kemungkinan disebabkan tuntutan menuju masa dewasa saat ini telah berubah (Papalia \& Feldman, 2012). Kessler menemukan jika tantangan kesehatan mental sering muncul pertama kali saat atau sesaat sebelum usia perkuliahan -secara umum (Tavakoli, Broyles, Reid, Sandoval, \& CorreaFernández, 2018). Pada masa ini individu atau mahasiswa sangat rentan akan tekanan psikologis, yang mungkin disebabkan akan masa transisi yang ditandai dengan eksplorasi diri, ketidakstabilan dan tantangan baru (Arnett, 2015; Tavakoli et al., 2018). Menurut January et al., (2018), mahasiswa memiliki tingkat kecemasan yang lebih tinggi dibandingan populasi lainnya. Secara global diperkirakan 20-25\% mahasiswa mengalami stres dan 50\% diantaranya mengalaminya dalam bentuk kecemasan (Haidar, De Vries, Karavetian, \& El-Rassi, 2018). Kecemasan yang terjadi pada mahasiswa dapat menyebabkan terganggunya performa akademik dan kualitas hidup mereka (January et al., 2018, Tavakoli et al., 2018).

Beberapa faktor yang memengaruhi kecemasan mahasiswa yaitu tekanan akademik, tuntutan tugas, kekhawatiran akan kesehatan, kompetisi dengan rekan akademis, kebutuhan untuk menjadi unggul, masalah sosial, gangguan tidur, masalah finansial, ataupun abuse dan penganiayaan terhadap mahasiswa (January et al., 2018; Haidar et al., 2018). Salah satu faktor yang juga menyebabkan kecemasan pada mahasiswa yaitu ujian atau penilaian (Hanh et al., 2017). Ujian dan situasi evaluatif termasuk pemicu stress yang kuat karena mendasari keputusan yang penting berkaitan dengan status penilaian akademik individu (Weiner \& Craighead, 2010).

Pada dunia pendidikan, penilaian atau ujian merupakan suatu hal yang tidak dapat dipisahkan. Selain berguna untuk memberikan tanggapan kepada pelajar, hal ini berguna agar pengajar mengetahui kondisi pengetahuan yang dimiliki oleh anak didiknya. Hasil penilaian atau ujian ini memiliki dampaknya tersendiri. Ketika pelajar gagal pada suatu ujian, biasanya ia akan diizinkan untuk mengulang atau mengikuti remedial. Akan tetapi, kegagalan yang terus berulang dapat menyebabkan kerugian misalnya kerugian waktu karena tertunda untuk lulus ataupun sampai dampak terburuknya yaitu dikeluarkan dari studi. Sehingga penilaian atau ujian dapat menjadi kondisi yang menekan dan menyebabkan kecemasan bagi mahasiswa. Kecemasan ini disebut dengan test anxiety atau kecemasan evaluatif (Hanh et al., 2017).

Kecemasan evaluatif mengacu pada ketakutan akan kegagalan atau ancaman terhadap ego jika terjadi kegagalan dalam penilaian atau ujian (Guraya et al., 2018). Bagi sebagian pelajar kondisi ini dapat memotivasi diri mereka akan tetapi bagi sebagian lainnya kondisi ini justru menyebabkan distress yang dapat berdampak kepada perkembangan studi mereka (Hanh et al., 2017). Kecemasan evaluatif digambarkan sebagai faktor krusial yang bertanggungjawab akan berbagai hasil yang tidak menguntungkan bagi pelajar termasuk kognitif yang buruk, prestasi sekolah yang rendah, tekanan psikologis, dan kesehatan yang buruk (Weiner \& Craighead, 2010; Pekrun, 2015). Kecemasan evaluatif menyebabkan tekanan pada siswa dan juga terganggunya performa tes. Selain itu hal ini juga dapat memicu munculnya bias akan tes yang dijalani ataupun menyebabkan hasil pengujian kognitif individu tidak valid. 
Kecemasan evaluatif terbukti memiliki hubungan negatif dengan pencapaian dan kemampuan sekolah baik pada tingkat sekolah menengah atas maupun tingkat kuliah (DordiNejad et al., 2011; Weiner \& Craighead, 2010). Tingginya kecemasan evaluatif juga meningkatkan tingkat kekhawatiran dan gangguan kognitif, sehingga menyebabkan terganggunya kapasitas atensi, memori jangka pendek, pemecahan masalah, dan proses kognitif lainnya yang diperlukan untuk penyelesaian tes yang baik. Kecemasan evaluatif juga menyebabkan pola aversif akan motivasi, coping, dan strategi belajar yang mengganggu proses belajar dan perfoma. Akibatnya hal tersebut menyebabkan terganggunya kompetensi, self-efficacy, dan dapat menyebabkan kecemasan lebih lanjut. Sehingga kondisi tersebut menyebabkan timbulnya lingkaran masalah yang berkepanjangan. Akan tetapi, di Indonesia sendiri masih minim penelitian terkait kecemasan evaluatif baik pada jenjang sekolah ataupun perguruan tinggi.

Rumusan masalah pada penelitian ini adalah "bagaimana gambaran kecemasan evaluatif pada mahasiswa di salah satu universitas swasta di Jakarta"

\section{METODE PENELITIAN}

Penelitian ini dilakukan pada mahasiwa psikologi di salah satu universitas swasta di Jakarta. Pengambilan data dilakukan sesaat sebelum partisipan mengikuti kuis pada suatu mata kuliah. Jumlah partisipan dalam penelitian ini adalah 207 orang.

Pengambilan data dilakukan dengan menggunakan kuesioner Test Anxiety Inventory (TAI) yang disusun oleh Charles D. Spielberger. Kuesioner ini bersifat self-report dan paper-and-pencil based. Pada pengerjaannya, terdapat 20 butir pernyataan yang menanyakan mengenai gambaran secara umum yang dirasakan responden pada saat, sebelum ataupun sesudah situasi ujian atau penilaian. Kuesioner ini menggunakan skala Likert yang terdiri dari skor 1-4 yaitu hampir tidak pernah, kadang-kadang, sering dan hampir selalu.

Berdasarkan hasil uji normalitas dengan menggunakan Kolmogorov-Smirnov (Tabel 1) diketahui skor kecemasan evaluatif memiliki nilai $\mathrm{Z}=0.82$, $\mathrm{p}>0.05$. Hal ini berarti data skor kecemasan evaluatif tidak terdistribusi dengan normal.

Tabel 1. Uji normalitas TAI

\begin{tabular}{lrr} 
& & Test Anxiety \\
\hline N & & 207 \\
Normal Parameters & Mean & 39.7729 \\
Most Extreme Differences & Std. Deviation & 9.31080 \\
& Absolute & .082 \\
& Positive & .082 \\
Test Statistic & Negative & -.042 \\
Asymp. Sig. (2-tailed) & & .082 \\
\hline a. Test distribution is Normal. & & $.002^{\mathrm{c}}$ \\
b. Calculated from data. & & \\
c. Lilliefors Significance Correction. & & \\
\end{tabular}




\section{HASIL DAN PEMBAHASAN}

Sebanyak 207 partisipan yang telah mengisi kuesioner, terdapat 43 (20.8\%) partisipan laki-laki dan 164 (79.2) partisipan perempuan. Usia rata-rata partisipan berkisar dari 19-24 tahun, dengan usia rata-rata 20 tahun. Partisipan terbagi menjadi beberapa angkatan dengan angkatan 2017 terdri dari $1(0.5 \%)$ orang, 2016 terdiri dari $191(92.3 \%)$ orang, 2015 terdiri dari $9(4.3 \%)$ orang, 2014 terdiri dari 4 (1.9\%) orang, 2013 teridiri dari 1 (0.5\%) orang, dan 2012 terdiri dari $1(0.5 \%)$ orang.

Tabel 2. Descriptive Statistics

\begin{tabular}{lrrrrr}
\hline & N & Minimum & Maximum & Mean & Std. Deviation \\
\hline Kecemasan Evaluatif & 207 & 23.00 & 71.00 & 39.7729 & 9.31080 \\
Valid N (listwise) & 207 & & & & \\
\hline
\end{tabular}

Tabel 2 merepresentasikan tingkat kecemasan evaluatif mahasiswa. Berdasarkan tabel 2, skor tertinggi adalah 71 , skor terendah adalah 23 , dan rata-rata skor adalah 39.77 . Hal ini berarti secara umum tingkat kecemasan evaluatif mahasiswa berada dalam kategori yang rendah. Hal ini kemungkinan dapat disebabkan oleh tingkat kesulitan atau tuntutan tes dari kuis yang dijalani tidak seberat dengan ujian tengah semester atau ujian akhir yang memiliki bobot nilai yang lebih besar dibandingkan dengan kuis. Menurut Spielberger, tingkat kecemasan evaluatif juga dapat dipengaruhi oleh beberapa faktor lain seperti pengalaman masa lalu individu, permasalahan yang harus diselesaikan, dan faktor situasional lainnya yang dapat meningkatkan kecemasan (Zeidner, 1998). Beberapa individu dapat memiliki kecemasan evaluatif dikarenakan memiliki motivasi yang rendah untuk berhasil dalam tugas akademik, memiliki keterampilan belajar yang buruk, memiliki kemampuan intelektual yang rendah, gagal memenuhi harapan sosial, takut akan hukuman orangtua, atau memiliki kecenderungan perfeksionis untuk melampaui batas dan merasa tidak puas dengan nilai yang kurang sempurna.

Tabel 3. Tingkat kecemasan evaluatif

\begin{tabular}{ccccc}
\hline Kategori & Range & Frekuensi & Presentase \\
\hline Rendah & $20-40$ & 119 & $(57 \%)$ \\
Sedang & $41-61$ & 85 & $(41 \%)$ \\
Tinggi & $62-82$ & 3 & $(1 \%)$ \\
& Total & & 207 & $(100 \%)$ \\
\hline
\end{tabular}

Tabel 4. Karakteristik sosiodemografik partisipan $(\mathrm{n}=207)$

\begin{tabular}{llrrr}
\hline Karakteristik & \multicolumn{2}{c}{ Rendah (\%) } & \multicolumn{3}{c}{ Tedang (\%) } & \\
\hline Jenis Kelamin & & & & \\
$\quad$ Laki-laki & $:$ & $27(62.8)$ & $15(34.9)$ & $1(2.3)$ \\
\multicolumn{1}{c}{$\begin{array}{c}\text { Perempuan } \\
\text { Usia (tahun) }\end{array}$} & $:$ & $92(56.1)$ & $70(42.7)$ & \\
& & & & \\
19 & $:$ & $4(44.4)$ & $5(55.6)$ & $0(0.0)$ \\
20 & $:$ & $78(60.5)$ & $49(38.0)$ & $2(1.6)$ \\
21 & $:$ & $27(54.0)$ & $22(44.0)$ & $1(2.0)$ \\
22 & $:$ & $7(58.3)$ & $5(41.7)$ & $0(0.0)$ \\
23 & $:$ & $3(75.0)$ & $1(25.0)$ & $0(0.0)$ \\
\hline
\end{tabular}




\begin{tabular}{rrrrrr}
\hline \multirow{5}{*}{ Angkatan } & 24 & $:$ & $0(00.0)$ & $3(100)$ & $0(0.0)$ \\
& & & & \\
& 2012 & $:$ & $1(100)$ & $0(00.0)$ & $0(0.0)$ \\
& 2013 & $:$ & $0(00.0)$ & $1(100)$ & $0(0.0)$ \\
2014 & $:$ & $1(25.0)$ & $3(75.0)$ & $0(0.0)$ \\
2015 & $:$ & $5(55.6)$ & $3(33.3)$ & $1(11.1)$ \\
2016 & $:$ & $111(58.1)$ & $78(40.8)$ & $2(1.0)$ \\
& 2017 & $:$ & $1(100)$ & $0(00.0)$ & $0(0.0)$ \\
\hline
\end{tabular}

Berdasarkan data, dari 207 partisipan terdapat 119 (57\%) mahasiswa dengan tingkat kecemasan evaluatif rendah, 85 (41\%) mahasiswa dengan tingkat kecemasan evaluatif sedang, 3 (1\%) mahasiswa dengan tingkat kecemasan evaluatif tinggi. Apabila ditinjau dari jenis kelamin, pada laki-laki terdapat 27 orang $(62.8 \%)$ memiliki tingkat kecemasan evaluatif rendah, 15 orang (34.9\%) memiliki tingkat kecemasan evaluatif sedang, dan 1 orang (2.3\%) memiliki tingkat kecemasan evaluatif tinggi. Sedangkan pada perempuan terdapat 92 orang (56\%) memiliki tingkat kecemasan evaluatif rendah, 70 orang (42.7\%) memiliki tingkat kecemasan evaluatif sedang, dan 2 orang (1.2\%) memiliki tingkat kecemasan evaluatif tinggi.

Berdasarkan rata-rata tidak terdapat perbedaan signifikan antara tingkat kecemasan evaluatif mahasiwa perempuan dan laki-laki. Masing-masing memiliki rata-rata tingkat kecemasan evaluatif dalam kategori rendah dengan mahasiswa perempuan memiliki rata-rata skor kecemasan evaluatif 39.96 dan mahasiswa laki-laki memiliki rata-rata skor kecemasan evaluatif 39.04. Berdasarkan usia dan angkatan, juga tidak terdapat perbedaan signfikan skor kecemasan evaluatif. Pada angkatan 2016 yang mengambil mata kuliah dengan tepat waktu, rata-rata skor kecemasan evaluatif adalah 39.77. Sedangkan pada angkatan yang mengambil mata kuliah lebih cepat atau tidak sesuai dengan angkatannya memiliki rata-rata skor kecemasan evaluatif yang sedikit lebih tinggi dengan skor 39.81 .

Menurut Javanbakht dan Hadian (2014), tingkat kecemasan evaluatif dapat muncul berbeda-beda serta pada waktu yang juga berbeda. Hal ini bergantung pada persepsi individu akan tingkat kesulitan ujian yang dilakukan pada suatu periode penialan. Berdasarkan hasil penelitian ditemukan beragam faktor penyebab kecemasan evaluatif yang dialami partisipan yaitu adanya tuntutan yang berasal dari orangtua, keluarga, atau pemberi beasiswa; pengalaman kurang menyenangkan; kondisi organik atau psikis individu; urutan kelahiran; pembuktian diri di sosial; dan jurusan yang dipilih. Tuntutan orangtua merupakan faktor yang paling sering ditemui dari hasil pengambilan data. Hasil penelitian Putwain, Woods dan Symes (2010) menunjukkan jika tekanan orangtua berhubungan dengan kekhawatiran berlebihan, pikiran tidak relevan, dan simptom tubuh yang lebih berat yang dialami individu di situasi ujian. Menurut Putwain et al. (2010) hal ini menunjukkan tekanan orang tua berhubungan dengan meningkatnya kecemasan evaluatif.

\section{KESIMPULAN DAN SARAN}

Berdasarakan penelitian yang dilakukan kepada 207 partisipan, didapatkan hasil bahwa rata-rata mahasiswa yang mengikuti sebagai partisipan memiliki skor kecemasan evaluatif yang rendah. Terdapat 119 mahasiswa memiliki tingkat kecemasan evaluatif yang rendah, 85 mahasiswa memiliki tingkat kecemasan evaluatif sedang, dan hanya terdapat 3 mahasiswa yang memiliki tingkat kecemasan evaluatif tinggi. 
Saran pada penelitian selanjutnya yang ingin melihat kecemasan evalutatif pada mahasiwa adalah agar menambah mahasiswa dengan jurusan yang berbeda atau dari universitas yang berbeda agar hasil lebih dapat digeneralisasikan. Selain itu, penelitian selanjutnya diharapkan dapat mempertimbangkan faktor-faktor lain yang memengaruhi aspek kecemasan evaluatif seperti misalnya persepsi tingkat kesulitan individu terhadap tes yang akan dijalani, bentuk tes yang akan dijalani, jenis tes yang akan dilakukan, atau riwayat khusus pada individu seperti kesehatan fisik dan mental. Penelitian ini diharapkan dapat menjadi gambaran dan informasi mengenai kondisi psikologis mahasiswa. Peneliti juga mengharapkan hasil penelitian ini dapat menjadi informasi yang berguna untuk institusi pendidikan atau tenaga pendidik untuk menyediakan sarana preventif atau memberikan tindak lanjut bagi para mahasiswa yang mengalami kendala terkait kecemasan evaluatif.

\section{Ucapan Terima Kasih (acknowledgement)}

Peneliti mengucapkan terima kasih kepada seluruh partisipan yang telah bersedia meluangkan waktunya untuk mengikuti penelitian ini. Ucapan terima kasih peneliti sampaikan juga kepada seluruh pihak yang terlibat khususnya fakultas dan dosen pengampu mata kuliah yang telah mengizinkan peneliti untuk melakukan penelitian dan pengambilan data kepada para mahasiwa.

\section{REFERENSI}

Arnett, J. J. (2015). Emerging adulthood: The winding road from the late teens through the twenties (2nd ed.). New York, NY, US: Oxford University Press.

de Lijster, J. M., Dierckx, B., Utens, E. M., Verhulst, F. C., Zieldorff, C., Dieleman, G. C., \& Legerstee, J. S. (2017). The age of onset of anxiety disorders: a meta-analysis. Canadian Journal of Psychiatry. Revue Canadienne de Psychiatrie, 62(4), 237.

DordiNejad, F. G., Hakimi, H., Ashouri, M., Dehghani, M., Zeinali, Z., Daghighi, M. S., \& Bahrami, N. (2011). On the relationship between test anxiety and academic performance. Procedia-Social and Behavioral Sciences, 15, 3774-3778.

Grupe, D. W., \& Nitschke, J. B. (2013). Uncertainty and anticipation in anxiety: an integrated neurobiological and psychological perspective. Nature Reviews Neuroscience, 14(7), 488. doi:10.1038/nrn3524.

Guraya, S. Y., Guraya, S. S., Habib, F., AlQuiliti, K. W., \& Khoshhal, K. I. (2018). Medical students perception of test anxiety triggered by different assessment modalities. Medical teacher, 1-7. https://doi.org/10.1080/0142159X.2018.1465178

Hanh, H., Kropp, P., Kirschstein, T., Rücker, G., \& Müller-Hilke, B. (2017). Test anxiety in medical school is unrelated to academic performance but correlates with an effort/reward imbalance. PloS one, 12(2), e0171220.

Haidar, S. A., De Vries, N. K., Karavetian, M., \& El-Rassi, R. (2018). Stress, anxiety, and weight gain among university and college students: a systematic review. Journal of the Academy of Nutrition and Dietetics, 118(2), 261-274.

Helsley, J. D., \& Vanin, J. R. (2008). Anxiety disorders a pocket guide for primary care. Humana Press.

January, J., Madhombiro, M., Chipamaunga, S., Ray, S., Chingono, A., \& Abas, M. (2018). Prevalence of depression and anxiety among undergraduate university students in lowand middle-income countries: a systematic review protocol. Systematic reviews, 7(1), 57. https://doi.org/10.1186/s13643-018-0723-8

Javanbakht, N., \& Hadian, M. (2014). The effects of test anxiety on learners' reading test performance. Procedia-Social and Behavioral Sciences, 98, 775-783. doi:10.1016/j.sbspro.2014.03.481 
Kementrian Kesehatan Republik Indonesia. (2016, Oktober). Peran keluarga dukung kesehatan jiwa masyarakat. http://www.depkes.go.id/article/print/16100700005/peran-keluargadukung-kesehatan-jiwa-masyarakat.html

Kementrian Kesehatan Republik Indonesia. (2018). Hasil utama riskesdas 2018. http://www.depkes.go.id/resources/download/infoterkini/materi_rakorpop_2018/Hasil\%20Riskesdas\%202018.pdf

Papalia D. E. \& Feldman, R. D., Martorell, G. (2012). Experience human development. New York, NY: Mc-Graw-Hill.

Pedrelli, P., Nyer, M., Yeung, A., Zulauf, C., \& Wilens, T. (2015). College students: mental health problems and treatment considerations. Academic Psychiatry, 39(5), 503-511.

Pekrun, R., \& Stephens, E. J. (2015). Test anxiety and academic achievement. In International Encyclopedia of the Social \& Behavioral Sciences (2nd ed, 244-249) https://doi.org/10.1016/B978-0-08-097086-8.26064-9

Putwain, D.W., Woods, K.A. \& Symes, W. (2010). Personal and situational predictors of test anxiety of students in post-compulsory education. British Journal of Educational Psychology, 80, 137-160.

Ritchie, H. \& Roser, M. (2018, April). Mental health. Our World in Data. https://ourworldindata.org/mental-health\#prevalence-of-mental-health-and-substanceuse-disorders

Tavakoli, N., Broyles, A., Reid, E. K., Sandoval, J. R., \& Correa-Fernández, V. (2018). Psychological inflexibility as it relates to stress, worry, generalized anxiety, and somatization in an ethnically diverse sample of college students. Journal of Contextual Behavioral Science.

Weiner, I. B., \& Craighead, W. E. (2010). The Corsini encyclopedia of psychology (Vol. 4). John Wiley \& Sons.

Zeidner, M. (1998). Test anxiety: The state of the art. Springer Science \& Business Media. 